\title{
De novo adult acute myeloid leukemia with two new mutations in juxtatransmembrane domain of the FLT3 gene: a case report
}

\author{
Ismael F. Alarbeed ${ }^{1 *}$, Abdulsamad Wafa2, Faten Moassass², Bassel Al-Halabi², Walid Al-Achkar², Thomas Liehr ${ }^{2,3}$ \\ and Imad Aboukhamis'
}

\begin{abstract}
Background: Approximately 30\% of adult acute myeloid leukemia (AML) acquire within fms-like tyrosine kinase 3 gene (FLT3) internal tandem duplications (FLT3/ITDs) in their juxtamembrane domain (JMD). FLT3/ITDs range in size from three to hundreds of nucleotides, and confer an adverse prognosis. Studies on a possible relationship between of FLT3/ITDs length and clinical outcomes in those AML patients were inconclusive, yet.

Case presentation: Here we report a 54-year-old Arab male diagnosed with AML who had two FLT3-ITD mutations in addition to NPM1 mutation. Cytogenetic approaches (banding cytogenetics) and fluorescence in situ hybridization (FISH) using specific probes to detect translocations $\mathrm{t}(8 ; 21), \mathrm{t}(15 ; 17), \mathrm{t}(16 ; 16), \mathrm{t}(12 ; 21)$, and deletion del(13q)) were applied to exclude chromosomal abnormalities. Molecular genetic approaches (polymerase chain reaction (PCR) and the Sanger sequencing) identified a yet unreported combination of two new mutations in FLT3-ITDs. The first mutation induced a frameshift in JMD, and the second led to a homozygous substitution of c.1836T>A (p.F612L) also in JMD. Additionally a NPM1 type A mutation was detected. The first chemotherapeutic treatment was successful, but 1 month after the initial diagnosis, the patient experienced a relapse and unfortunately died.

Conclusions: To the best of our knowledge, a combination of two FLT3-ITD mutations in JMD together with an NPM1 type A mutation were not previously reported in adult AML. Further studies are necessary to prove or rule out whether the size of these FLT3-ITDs mutations and potential other double mutations in FLT3-ITD are correlated with the observed adverse outcome.
\end{abstract}

Keywords: Acute myeloid leukemia, FLT3-ITDs, ITDs size, Sanger sequencing, Prognostic factors

\section{Background}

In patients with acute myeloid leukemia (AML) genetic diagnostics were performed in the past mainly by cytogenetics and molecular cytogenetics. In recent years also tumor markers were added, which rely on molecular genetic methods [1].

\footnotetext{
*Correspondence: dr.ismaelalarbeed@gmail.com

${ }^{1}$ Department of Microbiology, Hematology and Immunology, Faculty of Pharmacy, Damascus University, Ministry of High Education, Damascus, Syria

Full list of author information is available at the end of the article
}

The fms-like tyrosine kinase 3 (FLT3) gene encodes a class III tyrosine kinase receptor for the FLT3 ligand, which is normally expressed in $\mathrm{CD}^{+} 4^{+}$hematopoietic stem/progenitor cells, and plays a fundamental role in both normal and leukemic hematopoiesis [2]. Internal tandem duplications (ITDs) of the FLT3 gene (FLT3/ ITDs) represent one of the most common molecular abnormalities in patients with AML. They are detectable in around $25-30 \%$ of all patients [3, 4]. ITDs consist of in-frame insertions of duplicated sequences localized in the juxtamembrane domain (JMD) of the FLT3 molecule. Their presence results in a constitutive, ligand original author(s) and the source, provide a link to the Creative Commons licence, and indicate if changes were made. The images or other third party material in this article are included in the article's Creative Commons licence, unless indicated otherwise in a credit line to the material. If material is not included in the article's Creative Commons licence and your intended use is not permitted by statutory regulation or exceeds the permitted use, you will need to obtain permission directly from the copyright holder. To view a copy of this licence, visit http://creativecommons.org/licenses/by/4.0/. The Creative Commons Public Domain Dedication waiver (http://creativeco mmons.org/publicdomain/zero/1.0/) applies to the data made available in this article, unless otherwise stated in a credit line to the data. 
independent activation of the tyrosine kinase activity of the FLT3 receptor; this is responsible for abnormal proliferation and differentiation of leukemic stem cells [2]. In AML constitutive activation of kinase domain happens due to disruption of auto-inhibitory interaction between JMD and the activation loop, which normally stabilizes the inactive kinase, and at the same time protects ATP binding pocket $[5,6]$. FLT3/ITDs also protect leukemic cells from the damaging chemotherapeutic agents [7].

It was suggested that an increasing length of additional sequences like ITDs may influence the grade of tyrosine kinase activity of the FLT3 receptor, and could (1) lead progressively to increasing activation levels and (2) to worsen the overall survival (OS) in affected patients. Still, the results of studies which investigated the impact of ITD length on the clinical outcome are contradictory. Some studies confirming the aforementioned assumption [8-12], whereas others contradicted [13, 14].

Presence of FLT3/ITDs has been associated with an increased initial peripheral white blood cell (WBC) count and percentage of blast cells in bone marrow, a reduced disease-free survival (DFS) and OS, and a high relapse rate with an overall adverse prognosis. However, the rate of complete remission (CR) was not significantly affected [15-17]. Thus, a prognostic significance of FLT3/ ITDs has been suggested [8]. According to the National Comprehensive Cancer Network and the European LeukemiaNet (ELN) 2017, AML cases with cytogenetically normal karyotypes and FLT3/ITD mutation have a poor prognosis.

Besides in FLT3/ITD, mutations in nucleophosmin 1 (NPM1) gene represent the second most frequent molecular aberration in AML patients [18]. A combined status of mutated NPM1 and the wild type FLT3 gene $\left(N P M 1^{+} / F L T 3^{-}\right)$is a well-established favorable risk factor in younger adult patients, with less probability of relapse and prolonged survival [19-21]; these patients are not obliged to receive allogeneic hematopoietic stem cell transplantation [22]. Otherwise, co-occurrence of FLT3/ITD and NPM1 mutations was suggested to partially improve response rates, DFS and OS outcomes compared to AML-patients having exclusively FLT3/ ITD mutations. However, cases with mutations in FLT3/ ITD and NPM1 have worse prognosis than those having $\left(\mathrm{NPM1}^{+} / \mathrm{FLT3}^{-}\right)$[23].

Here, we present a unique case with two FLT3-ITDs mutations in JMD and an NPM1 type A gene mutation associated with adverse outcome.

\section{Case presentation}

In October 2019, a 54-year-old Arab male patient presented with 2 months history of fatigue, orthostatic hypotension followed by bruising on the lower right extremity, melena (present for one month only) and dyspnea II. Physical examination and computer tomographic scan showed hepatomegaly $(4 \mathrm{~cm})$. He had no familial history of malignancies and no social and environmental history of exposure to toxins or animals. Initial laboratory evaluation of peripheral blood $(\mathrm{PB})$ revealed white blood cells count (WBC) of $26.3 \times 10^{9} / 1$ (10\% were blasts). Pathologic examination of bone marrow (BM) aspirate characterized hybercellularity with $60 \%$ of blasts. Flow cytometric (FCM) analysis classified this case as AML-M2 according to world health organization (WHO) classification. The abnormal cell population (60\%) was positive for CD45 dim, CD34, HLADr, CD13, CD33 and expressed CD117 heterogeneously. Blasts cell population was negative for CD3, CD117, CD14, cCD3, cCD79a, CD14, CD11c, CD38, CD64, CD32, CD7, CD19, CD10, and CD5.

The patient was given standard treatment for AML including $3+7$ induction chemotherapy (daunorubicin $60 \mathrm{mg} / \mathrm{m}^{2}$ for 3 days and cytarabine $200 \mathrm{mg} / \mathrm{m}^{2}$ for 7 days). One month later, under treatment with $3+7$ protocol, the patient relapsed, i.e. his PB showed a WBC of $107 \times 10^{9} / \mathrm{l}$, anemia (hemoglobin level $\left.(\mathrm{Hgb})=8.8 \mathrm{~g} / \mathrm{dl}\right)$ and thrombocytopenia (Plt $93 \times 10^{9} / \mathrm{l}$ ). The patient was given re-induction with $3+7$ chemotherapy protocol (for more details see Table 1). Less than one month after relapse, the patient acquired additional severe symptoms such as neutropenia, neutropenic enterocolitis, and diabetes insipidus, and the patient unfortunately passed away due to respiratory and cardiac arrest. No autopsy was performed. The patient's brother agreed with the scientific evaluation of this case and the study was approved by the ethical committee of Pharmacy faculty at Damascus University, Ministry of High Education, Syria review Board, No. 2/2019.

Chromosome analysis using GTG-banding was performed on BM sample taken prior to chemotherapy according to standard protocols [24]. A normal male karyotype was diagnosed. Fluorescence in situ hybridization (FISH) using specific probes to detect translocations $\mathrm{t}(8 ; 21), \mathrm{t}(15 ; 17), \mathrm{t}(16 ; 16), \mathrm{t}(12 ; 21)$, and deletion del(13q), were applied to excluded chromosomal abnormalities, too, as previously reported [24].

For molecular analyses, whole genomic DNA was extracted from PB cells (EDTA-blood) prior to chemotherapy treatment. Polymerase chain reaction (PCR) amplification of genomic DNA and Sanger sequencing were used to screen for the presence of mutations of the following genes: FLT3/ITD (exons 11 and 12), FLT3-KTD and NPM1; using specific primers for each mutation previously reported [25]. ITDs were confirmed by Sanger sequence analysis; the wild-type band of $330 \mathrm{bp}$ length, and other differently sized PCR products were identified in our patient (Fig. 1) using the ABI Prism 310 genetic 


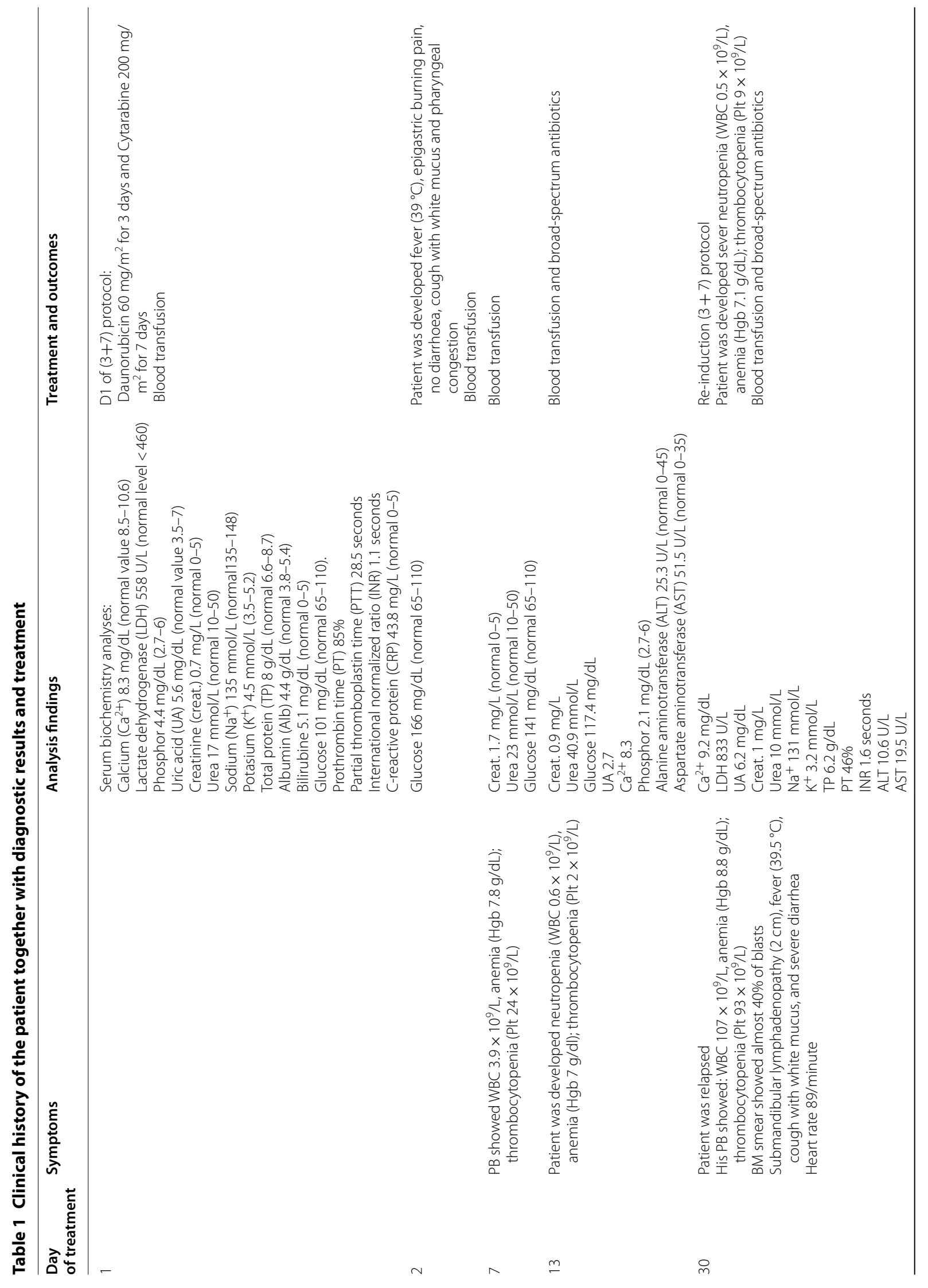




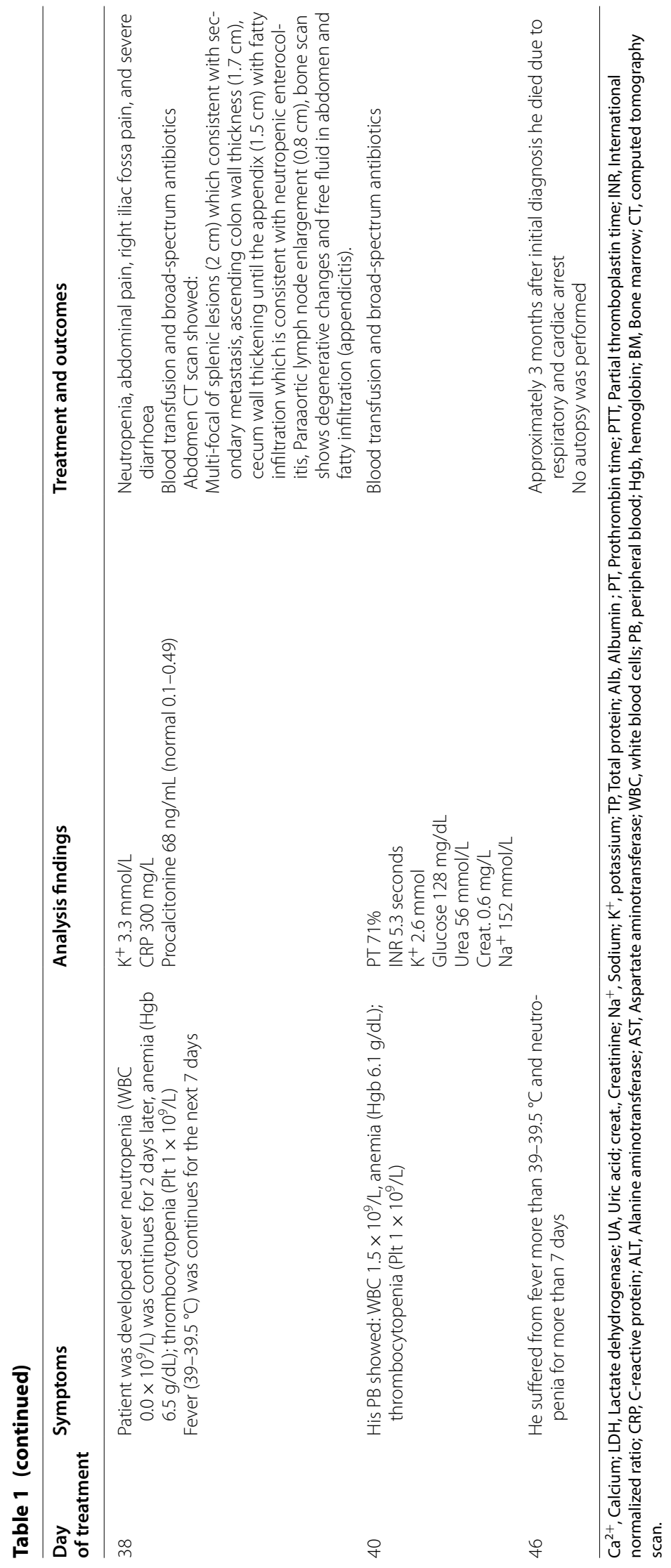




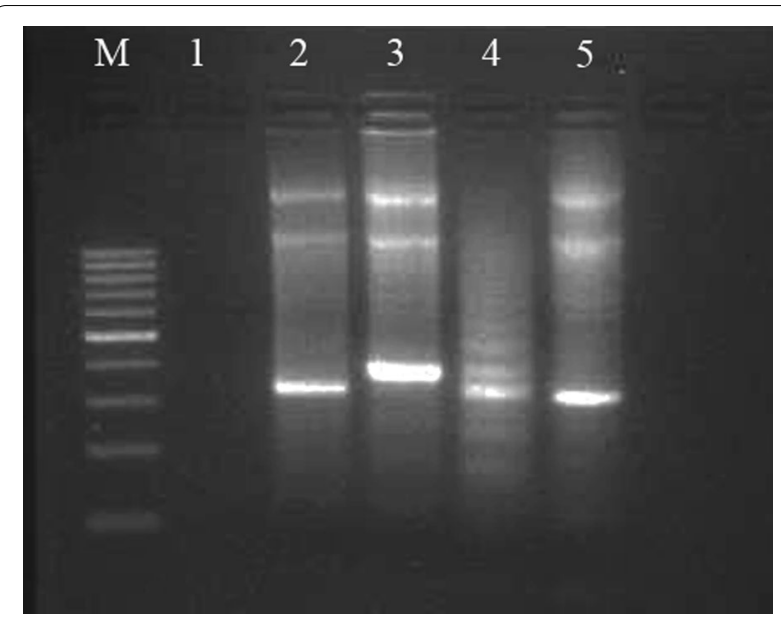

Fig. 1 Agarose gel electrophoresis. The PCR amplification products of ITD. M indicates the molecular weight marker (100 bp); line 1, blank PCR products; lines 2 and 5, wild-type FLT3-ITD; line 3, the band of 390 bp in our patient; and line 4, mutant FLT3-ITD.

analyzer (Applied Biosystems, Foster City, CA, USA). Two novel frameshift mutations of the JMD in FLT3-ITD were identified in our patient (see also Fig. 2):

mutation $1: \quad$ c.1779-1780insTTTCAGAGA A TA TGA ATA TGA TC T CAA A TG GGA GT T T C C A A A G A A A T T T A G A G T A G G (p.D593-F594insREYEYDLKWEFPRENLEF).

mutation 2: homozygous substitution c.1836T $>$ A (p.F612L).

A D835 mutation was not detected by FLT3-KTD test in our patient. However, he had also NPM1 type A mutation (data not shown).

\section{Discussion and conclusions}

Here we report the first case of an adult AML patient with normal karyotype, who had one NPM1 type A and two frameshift FLT3-ITD mutations. The first frameshift FLT3-ITD was never reported before (COSMIC database for somatic samples from hematopoietic and lymphoid tissue), whereas the second mutation has already been observed, but as heterozygous variant (COSV54057677).

The present case supports previous findings [8-12], which suggested that long ITDs are associated with adverse OS, a higher incidence for relapse and a negative impact on clinical outcomes in AML patients post chemotherapy.

Of special interest, is the suggestion that the complications of intense chemotherapy, as observed in our patient (see Table 1), could also have been promoted by the observed combination of mutation events. The observed neutropenia, is associated with the risk for developing serious and complicated infections or even sepsis [26-28]. Also neutropenic enterocolitis (NE), a necrotizing process usually localized to the ascending colon, cecum, and terminal ileum $[29,30]$ can appear in $15 \%$ of AML patients treated with a combination of Idarubicin and Cytosine arabinoside [31], It also associated with increased mortality [32]. Finally, central diabetes insipidus (DI) is a rare complication in AML and myelodysplastic syndrome (MDS) cases with less than 100 cases reported in literature [33]. Central DI can precede the diagnosis of AML or MDS or it can manifest during treatment and was thought to confer a poor prognosis [33]. The pathogenesis of central DI in AML and MDS may be secondary to leukemic infiltration of the infundibulum, hemorrhage, thrombosis, infection, or autoimmunity [34].

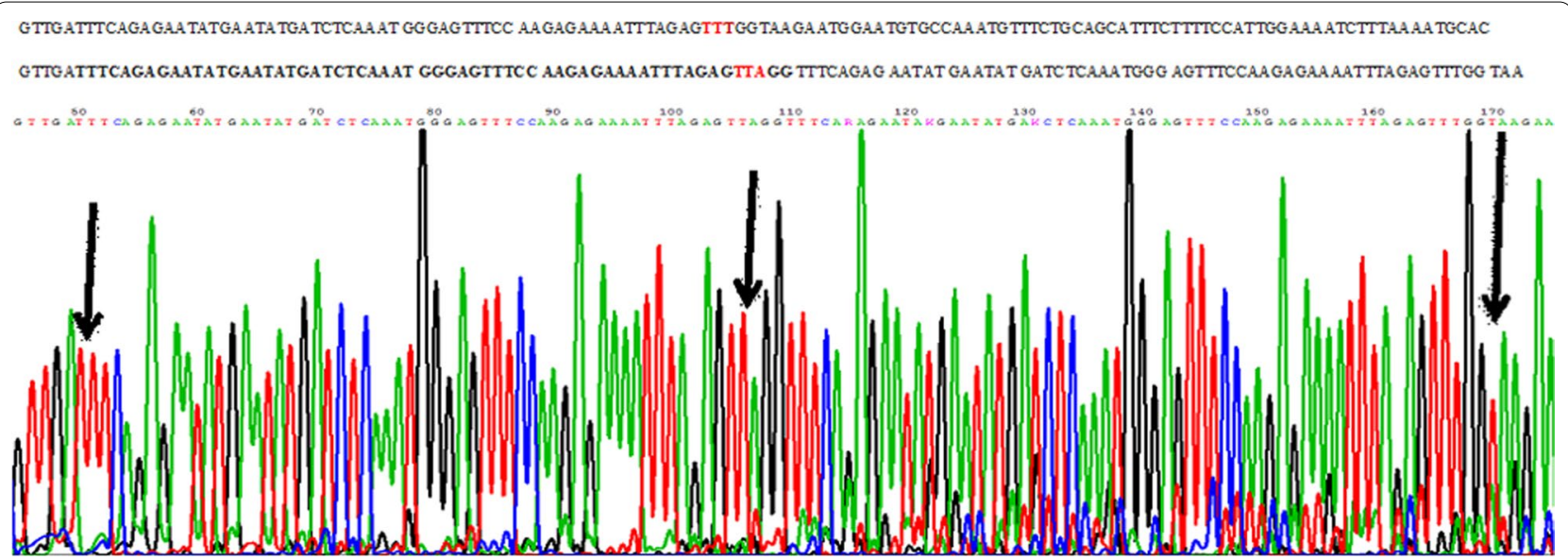

Fig. 2 Sanger sequence of the ITD mutation, revealed an insertion and a duplicated mutation sequence, respectively. 
Further studies are needed to prove or rule out whether the size of the FLT3-ITDs mutation and the double mutations in FLT3-ITD are correlated with an adverse prognosis. Also, more research is needed to see if chemotherapy-complications as observed here can be omitted by the application of other treatment regimes.

\section{Abbreviations}

AML: Acute myeloid leukemia; BM: Bone marrow; CR: Complete remission; DFS: Disease-free survival; DI: Diabetes insipidus; FISH: Fluorescence in situ hybridization; FCM: Flow cytometric; FLT3: Fms-like tyrosine kinase 3 gene; JMD: Juxtamembrane domain; ITDs: Internal tandem duplications; MDS: Myelodysplastic syndrome; NPM1: Nucleophosmin 1 gene; NE: Neutropenic enterocolitis; OS: Overall survival; PB: Peripheral blood; WBC: White blood cells; WHO: World health organization.

\section{Acknowledgements}

We express gratitude to our Research Team, Faculty of Pharmacy of Damascus University and Atomic Energy Commission of SYRIA (AECS) for their support.

\section{Authors' contributions}

IFA and IA performed provided the clinical data and the chemotherapy plan; AW, FM, BA and WA performed the cytogenetic, molecular cytogenetic and molecular genetic analyses; IFA, TL, IA and AW drafted the paper and all authors worked on the final version of the paper. All authors read and approved the final manuscript.

\section{Funding}

There was no funding available for this research

\section{Availability of data and materials}

All relevant data and material is included in this publication.

\section{Ethics approval and consent to participate}

Study procedures were reviewed and approved by the ethical committee of the Atomic Energy Commission, Damascus, Syria Review Board. Written informed consent was obtained from all subjects prior to participation.

\section{Consent for publication}

Written informed consent was obtained from the patient's brother for publication of this case report and accompanying images. A copy of the written consent is available for review by the Editor-in-Chief of this journal.

\section{Competing interests}

The authors declare that they have no competing interests.

\section{Author details \\ ${ }^{1}$ Department of Microbiology, Hematology and Immunology, Faculty of Pharmacy, Damascus University, Ministry of High Education, Damascus, Syria. ${ }^{2}$ Department of Molecular Biology and Biotechnology, Human Genetics Division, Atomic Energy Commission, Damascus, Syria. ${ }^{3}$ Jena University Hos- pital, Institute of Human Genetics, Friedrich Schiller University, Am Klinikum 1, 07747 Jena, Germany.}

Received: 15 September 2020 Accepted: 16 November 2020 Published online: 26 January 2021

\section{References}

1. Kirtonia A, Pandya G, Sethi G, Pandey AK, Das BC, Garg M. A comprehensive review of genetic alterations and molecular targeted therapies for the implementation of personalized medicine in acute myeloid leukemia. J Mol Med (Berl). 2020;98:1069-91.

2. Stirewalt DL, Radich JP. The role of FLT3 in haematopoietic malignancies. Nat Rev Cancer. 2003;3:650-65.
3. Schnittger S, Schoch C, Dugas M, Kern W, Staib P, Wuchter C, et al. Analysis of FLT3 length mutations in 1003 patients with acute myeloid leukemia: correlation to cytogenetics, FAB subtype, and prognosis in the AMLCG study and usefulness as a marker for the detection of minimal residual disease. Blood. 2002;100:59-66.

4. Patnaik MM. The importance of FLT3 mutational analysis in acute myeloid leukemia. Leuk Lymphoma. 2018;59:2273-86.

5. Griffith J, Black J, Faerman C, Swenson L, Wynn M, Lu F, et al. The structural basis for autoinhibition of FLT3 by the juxtamembrane domain. Mol Cell. 2004;13:169-78.

6. Chan PM. Differential signaling of Flt3 activating mutations in acute myeloid leukemia: a working model. Protein Cell. 2011;2:108-15.

7. Lagunas-Rangel FA, Chávez-Valencia V. FLT3-ITD and its current role in acute myeloid leukaemia. Med Oncol. 2017;34:114.

8. Stirewalt DL, Kopecky KJ, Meshinchi S, Engel JH, Pogosova-Agadjanyan EL, Linsley J, et al. Size of FLT3 internal tandem duplication has prognostic significance in patients with acute myeloid leukemia. Blood. 2006:107:3724-6.

9. Kusec R, Jaksic O, Ostojic S, Kardum-Skelin I, Vrhovac R, Jaksic B. More on prognostic signifi cance of FLT3/ITD size in acute myeloid leukemia (AML). Blood. 2006;108:405-6.

10. Gale RE, Green C, Allen C, Mead AJ, Burnett AK, Hills RK, et al. The impact of FLT3 internal tandem duplication mutant level, number, size, and interaction with NPM1 mutations in a large cohort of young adult patients with acute myeloid leukemia. Blood. 2008;111:2776-84.

11. Liu SB, Dong HJ, Bao XB, Qiu QC, Li HZ, Shen HJ, et al. Impact of FLT3ITD length on prognosis of acute myeloid leukemia. Haematologica. 2019;104:e9-12.

12. Chen F, Sun J, Yin C, Cheng J, Ni J, Jiang L, et al. Impact of FLT3-ITD allele ratio and ITD length on therapeutic outcome in cytogenetically normal AML patients without NPM1 mutation. Bone Marrow Transplant. 2020;55:740-8.

13. Blau O, Berenstein R, Sindram A, Blau IW. Molecular analysis of different FLT3-ITD mutations in acute myeloid leukemia. Leuk Lymphoma. 2013;54:145-52.

14. Ponziani V, Gianfaldoni G, Mannelli F, Leoni F, Ciolli S, Guglielmelli P, et al. The size of duplication does not add to the prognostic significance of FLT3 internal tandem duplication in acute myeloid leukemia patients. Leukemia. 2006;20:2074-6.

15. Kottaridis PD, Gale RE, Frew ME, Harrison G, Langabeer SE, Belton AA, et al. The presence of a FLT3 internal tandem duplication in patients with acute myeloid leukemia (AML) adds important prognostic information to cytogenetic risk group and response to the first cycle of chemotherapy: analysis of 854 patients from the United Kingdom Medical Research Council AML 10 and 12 trials. Blood. 2001;98:1752-9.

16. Yanada M, Matsuo K, Suzuki T, Kiyoi H, Naoe T. Prognostic significance of FLT3 internal tandem duplication and tyrosine kinase domain mutations for acute myeloid leukemia: a meta-analysis. Leukemia. 2005;19:1345-9.

17. Canaani J, Labopin M, Huang XJ, et al. T-cell replete haploidentical stem cell transplantation attenuates the prognostic impact of FLT3-ITD in acute myeloid leukemia: a report from the Acute Leukemia Working Party of the European Society for Blood and Marrow Transplantation. Am J Hematol. 2018:93:736-44.

18. Schneider F, Hoster E, Schneider S, Dufour A, Benthaus T, Kakadia PM, et al. Age-dependent frequencies of NPM1 mutations and FLT3-ITD inpatients with normal karyotype AML (NK-AML). Ann Hematol. 2012;91:9-18.

19. Schnittger S, Schoch C, Kern W, Mecucci C, Tschulik C, Martelli MF, et al. Nucleophosmin gene mutations are predictors of favorable prognosis in acutemyelogenous leukemia with a normal karyotype. Blood. 2005;106:3733-9.

20. Thiede C, Koch S, Creutzig E, Steudel C, Illmer T, Schaich M, et al. Prevalence and prognostic impact of NPM1 mutations in 1485 adult patients with acute myeloid leukemia (AML). Blood. 2006;107:4011-20.

21. Döhner K, Schlenk RF, Habdank M, Scholl C, Rücker FG, Corbacioglu A, et al. Mutant nucleophosmin (NPM1) predicts favorable prognosis in youngeradults with acute myeloid leukemia and normal cytogenetics: interactionwith other gene mutations. Blood. 2005;106:3740-6.

22. Huang Y, Hu J, Lu T, Luo Y, Shi J, Wu W, et al. Acute myeloid leukemia patient with FLT3-ITD and NPM1 double mutation should undergo 
allogeneic hematopoietic stem cell transplantation in CR1 for better prognosis. Cancer Manag Res. 2019;11:4129-42.

23. Boddu P, Kantarjian H, Borthakur G, Kadia T, Daver N, Pierce S, et al. Cooccurrence of FLT3-TKD and NPM1 mutations defines a highly favorable prognostic AML group. Blood Adv. 2017;1:1546-50.

24. Al-Achkar W, Wafa A, Nweder MS. A complex translocation $t(5 ; 9 ; 22)$ in Philadelphia cells involving the short arm of chromosome 5 in a case of chronic myelogenous leukemia. J Exp Clin Cancer Res. 2007;26:411-5.

25. Rezaei N, Arandi N, Valibeigi B, Haghpanah S, Khansalar M, Ramzi M. FMS-like tyrosine kinase 3 (FLT3) and nucleophosmin 1 (NPM1) in Iranian adult acute myeloid leukemia patients with normal karyotypes: mutation status and clinical and laboratory characteristics. Turk J Haematol. 2017:34:300-6.

26. Döhner H, Weisdorf DJ, Bloomfield CD. Acute myeloid leukemia. N Engl J Med. 2015;373:1136-52.

27. Bodey GP, Buckley M, Sathe YS, Freireich EJ. Quantitative relationships between circulating leukocytes and infection in patients with acute leukemia. Ann Intern Med. 1966;64:328-40.

28. Hansen BA, Wendelbo Ø, Bruserud Ø, Hemsing AL, Mosevoll KA, Reikvam H. Febrile Neutropenia in Acute Leukemia. Epidemiology, Etiology, Pathophysiology and Treatment. Mediterr J Hematol Infect Dis. 2020;12:e2020009.

29. Zorrilla AFC, Herault LR, Casasbuenas A, Aponte DM, Ramos PL. Systematic review of case reports concerning adults suffering neutropenic enterocolitis. Clin Transl Oncol. 2006;8:31-8.
30. Mullassery D, Bader A, Battersby AJ, Mohammad Z, Jones EL, Parmar C, et al. Diagnosis, incidence, and outcomes of suspected typhlitis in oncology patients-experience in a tertiary pediatric surgical center in the United Kingdom. J Pediatr Surg. 2009;44:381-5.

31. Hogan WJ, Letendre L, Litzow MR, Tefferi A, Hoagland HC, Pruthi RK, et al. Neutropenic colitis after treatment of acute myelogenous leukemia with idarubicin and cytosine arabinoside. Mayo Clin Proc. 2002;77:760-2.

32. Ebert EC, Hagspiel KD. Gastrointestinal manifestations of leukemia. J Gastroenterol Hepatol. 2012;27:458-63.

33. Cull EH, Watts JM, Tallman MS, Kopp P, Frattini M, Rapaport F, et al. Acute myeloid leukemia presenting with panhypopituitarism or diabetes insipidus: a case series with molecular genetic analysis and review of the literature. Leuk Lymphoma. 2014;55:2125-9.

34. Müller Cl, Engelhardt M, Laubenberger J, Kunzmann R, Engelhardt R, Lübbert M. Myelodysplastic syndrome in transformation to acute myeloid leukemia presenting with diabetes insipidus: due to pituitary infiltration association with abnormalities of chromosomes 3 and 7. Eur J Haematol. 2002;69:115-9.

\section{Publisher's Note}

Springer Nature remains neutral with regard to jurisdictional claims in published maps and institutional affiliations.
Ready to submit your research? Choose BMC and benefit from:

- fast, convenient online submission

- thorough peer review by experienced researchers in your field

- rapid publication on acceptance

- support for research data, including large and complex data types

- gold Open Access which fosters wider collaboration and increased citations

- maximum visibility for your research: over 100M website views per year

At BMC, research is always in progress.

Learn more biomedcentral.com/submissions 